\title{
DIÁLOGO ENTRE AS INDÚSTRIAS CARBONÍFERAS E COMUNIDADE: PESQUISA DE PERCEPÇÃO COMUNITÁRIA COM BASE EM INDICADORES SOCIOAMBIENTAIS
}

Cláudia Nandi Formentin ${ }^{1}$

Marília Köenig²

Rosimeri Mizeeski ${ }^{3}$

\section{RESUMO}

O presente artigo visa a analisar a comunicação entre comunidade e o setor carbonífero da região Sul Catarinense, tendo, como paralelo o destino das áreas de passivo ambiental. O objeto de análise será a avaliação quantitativa de uma comunidade em que uma organização do setor carbonífero recuperou as áreas antes degradadas. Para que se entenda o contexto da pesquisa, um breve histórico do carvão mineral será exposto, bem como a descrição das ações de algumas empresas mineradoras da região de Criciúma.

Palavras-chave: Mineração. Comunidade. Responsabilidade socioambiental.

\footnotetext{
${ }^{1}$ Mestre, claudia.formentin@hotmail.com

${ }^{2}$ Mestre, marilia.koenig@satc.edu.br

33raduada, rossy_m@hotmail.com
} 


\section{INTRODUÇÃO}

As lembranças deixadas pela extração do carvão na região de Criciúma nem sempre são boas. A falta de leis que regulamentassem as questões ambientais, como o cuidado com o passivo, fez com que muitas áreas fossem impactadas. Na época, a falta de aparatos tecnológicos e os riscos inerentes aos trabalhadores, no momento de baixar às minas, também causaram acidentes e alarmaram as comunidades. Essa série de fatores contribuiu para que a imagem do carvão ficasse marcada negativamente no imaginário local.

Foi o carvão que motivou o desenvolvimento aos municípios do Sul Catarinense. A extração desse mineral ainda é uma realidade na região. Na atualidade, o carvão já não é mais o principal produto econômico. Entretanto, sua importância é indubitável. É o mineral que fornece a eletricidade utilizada nessas cidades (BELOLLI et. al., 2002). Diante da importância desse minério, o trabalho em conjunto da empresa com a comunidade é essencial. Seja na recuperação de áreas degradadas ou no desenvolvimento de estudos que possam auxiliar na criação de novas tecnologias para o setor carbonífero.

Para analisar se de fato as mineradoras têm um bom relacionamento com a comunidade minerada, bem como a participação em projetos socioambientais que beneficiem os moradores em geral, uma avaliação quantitativa será aplicada. Nela, se procurará entender como é feito esse trabalho e se a imagem do carvão ainda continua negativa nessas comunidades. $\mathrm{O}$ intuito deste trabalho é criar e aplicar indicadores socioeconômicos e ambientais que dêem, aos pesquisadores, a ideia de como esse diálogo tem ocorrido.

Serve, ainda, ao propósito de perceber qual a expectativa da comunidade pesquisada (bairro Ana Maria, Criciúma) com relação às áreas recuperadas pelas Empresas Rio Deserto.

\section{CARVÃO MINERAL: UM BREVE HISTÓRICO}

O carvão é uma massa formada por troncos, folhas e ganhos de vegetação em decomposição há cerca de 250 mil anos. A atuação da pressão, bactérias e outros agentes anaeróbicos favoreceram o seu surgimento. Os vários ciclos que as florestas podem ter sofrido durante milhões de anos deram origem às várias camadas diferentes de carvões.

A sua extração iniciou por volta do século XVIII, na Europa, mas foi com o processo da revolução industrial que a mineração ampliou sua demanda, já que era a principal fonte energética.

No século XX, ele acabou perdendo espaço para o petróleo. Todavia, ainda é muito utilizado em siderúrgicas e em usinas termoelétricas. Os principais produtores mundiais desse recurso são os Estados Unidos, China, Cazaquistão, Rússia, Polônia, Índia, Alemanha, Austrália e a África do Sul. 
Atualmente, ele é a segunda fonte energética mais utilizada no mundo. De acordo com Parejo (2011) o consumo de carvão representa cerca $23,3 \%$ no mundo e $6,6 \%$ no Brasil.

\subsection{A importância do minério no Brasil}

No Brasil, as principais regiões com grandes jazidas desse mineral se encontram em dois estados da região Sul: Rio Grande do Sul e Santa Catarina. No Rio Grande do Sul, a primeira mina de carvão foi aberta em 1855, em Arroio dos Ratos. A extração do minério desenvolveu-se concomitantemente ao desenvolvimento urbano, com a instalação da linha férrea para o transporte do carvão e mais tarde, pela construção de uma termoelétrica.

O Estado do Rio Grande do Sul possui a maior parte das reservas nacionais. Segundo dados da Associação Brasileira do Carvão Mineral (2012), 89,2\% das jazidas estão concentradas no estado gaúcho, totalizando 28,802 milhões de toneladas.

\subsubsection{A extração do minério em Santa Catarina}

Em Santa Catarina, a extração do carvão iniciou no final do século XIX, com uma expedição de uma companhia britânica, que acabou construindo a ferrovia Dona Tereza Cristina por volta de 1885. O carvão catarinense era considerado de baixa qualidade, não despertando o interesse dos desbravadores ingleses.

No entanto, durante a Primeira Guerra Mundial a demanda pelo mineral cresceu. Nessa época, novas empresas mineradoras se instalaram na região sul. Desde então o carvão sofreu diversas altas e baixas, mas foi nos anos de 1990 que ele teve sua maior crise. Conforme o exposto no site Carvão mineral, no início da década de 1990, o setor é desregulamentado por decreto do Governo Federal, o que fez com que toda a região Sul catarinense mergulhasse em profunda crise (BELOLLI et. al., 2002).

Entretanto, o setor vem obtendo recuperação, sobretudo com o desenvolvimento tecnológico e as pesquisas em torno da produção mais limpa do carvão mineral. Tecnologias vindas de outros países, por meio de pesquisas, estão sendo implantadas pelas mineradoras. O setor está se modernizando.

Atualmente, a extração é voltada para o parque termelétrico construído em Tubarão e gera aproximadamente quatro mil empregos diretos. No entanto o passivo ambiental deixado por décadas de extração também é uma realidade local. Hoje há aproximadamente, 5,38 mil hectares que precisam ser recuperados. A meta do cronograma da Procuradoria da República prevê que 58\% do total sejam recuperados até 2020. 
É indiscutível a importância que esse minério tem no desenvolvimento da região de Criciúma, contudo, é visível o passivo ambiental proveniente da extração. A acidez presente nas bacias hidrográficas da região, a poluição e degradação do solo e as perdas na fauna e flora, foram motivos suficientes para que o carvão configurasse uma imagem negativa diante da sociedade. Para modificar esse conceito e, por conseguinte, projetar uma imagem mais positiva da indústria carbonífera, faz-se necessárias ações que fomentem o diálogo do setor com as comunidades dantes impactadas. Sendo esta, aliás, a razão de ser do projeto que deu origem ao presente trabalho.

\title{
2.2 Conceitos e implicações da sustentabilidade: econômica e socioambiental
}

A definição de sustentabilidade ainda gera muitas discussões. Diante de tais divergências, se conceituará o termo de acordo com Scliar (2009). Segundo o autor, sustentabilidade deve ser a soma das políticas sociais, ambientais e econômicas, visando o futuro e a qualidade de vida. Dentro da mineração, Scliar (2009, p. 46) define o uso do termo como: "o aproveitamento das riquezas minerais, porém, minimizando os efeitos negativos provocados por uma lavra que tenha como único objetivo a rentabilidade do 'negócio'".

Dias (2009, p. 40), por sua vez, apresenta:

\begin{abstract}
a sustentabilidade em três dimensões: econômica, social e ambiental. No lado econômico é levado em consideração o aspecto da rentabilidade, "dar retorno ao investimento realizado pelo capital privado.No âmbito social, a organização deve proporcionar um bom ambiente de trabalho aos seus colaboradores. Além disso, deve caminhar lado a lado com as necessidades da comunidade em que está situada.

Do ponto de vista ambiental, deve a organização pautar-se pelo eco-eficiência dos seus processos produtivos, adotar a produção mais limpa, oferecer condições para o desenvolvimento de uma cultura ambiental organizacional, adotar uma postura de responsabilidade ambiental.
\end{abstract}

Dentre os três conceitos oriundos da sustentabilidade, tendo em vista o foco do presente artigo, dar-se-á maior evidência às implicações sociais e ambientais desta.

\subsection{Preservação e recuperação ambiental}

Tendo em vista o cenário em que se está trabalhando, a região carbonífera de Criciúma, torna-se imprescindível falar em recuperação ambiental. Tendo em vista a vasta área degradada pela extração do carvão, e agora em processo de recuperação. 
A sustentabilidade, quando focada na questão ambiental reforça a prevenção, e o desenvolvimento de políticas que divulguem isso como exemplo. No entanto as áreas outrora degradadas merecem atenção, e no caso de Criciúma, até a intervenção do Ministério Público.

De acordo com o artigo segundo do Decreto Federal 97.632/ 89, entende-se degradação ambiental como os "processos resultantes de danos no meio ambiente, pelos quais se perdem ou se reduzem algumas de suas propriedades, tais como, a qualidade ou capacidade produtiva dos recursos ambientais" (BRASIL, 1989).

Nesse âmbito, Scliar (2009, p. 49) alerta sobre a importância do monitoramento contínuo das áreas mineradas, permitindo assim, a previsão dos problemas ambientais. "Seguido de ações que viabilizem a sustentabilidade para a geração atual e garantam a sustentabilidade para as próximas gerações".

Além de recuperar, muitas empresas também criam políticas para preservar reservas, como será vislumbrado mais adiante, quando se discorrer sobre as ações das carboníferas da região.

\subsection{Comunidade participante das ações: o diálogo essencial}

O envolvimento da comunidade com as questões ambientais iniciou pela conscientização da importância dos recursos naturais. "Neste sentido, as sociedades estão aumentando suas exigências aos agentes mais diretamente envolvidos, particularmente administrações públicas e empresas" (DIAS, 2009, p. 69).

De acordo com Hilson (2002), a maior parte dos conflitos entre empresas mineradoras e a comunidade vem da falta de comunicação entre ambas. Isso contribui para o agravamento das questões ambientais da comunidade. Quando o diálogo é aberto é possível perceber pontos positivos como: contribuição do empreendimento para a infraestrutura escolar, de moradia e de transporte.

Sobre a ótica de avaliar se há uma comunicação entre empresa mineradora e comunidade, Lockie (2009, et. al.), aconselha a investigação dos impactos sociais para questões como previsão de cenários futuros e possibilidade de inserção dos residentes na tomada de decisão sobre o destino da área impactada.

\subsection{Ações ambientais promovidas pelas empresas carboníferas}

Antes de se analisar o resultado do diálogo travado pelos pesquisadores da parceria entre a Associação Beneficente da Indústria Carbonífera - Satc e Fundação de Amparo 
à Pesquisa e Inovação do Estado de Santa Catarina - FAPESC, com uma comunidade minerada sobre as empresas de extração de carvão, faz-se necessário que se conheçam as atividades dessas empresas ante as comunidades que atuam. Para isso, serão tomadas como base três carboníferas da região de Criciúma: Belluno Ltda., Criciúma S.A e Rio Deserto, sendo esta última, a mineradora presente na comunidade em que a pesquisa foi aplicada.

\subsubsection{Carbonífera Belluno}

As preocupações com o meio ambiente iniciam antes mesmo da extração do carvão na Carbonífera Belluno. De acordo com informações disponibilizadas no site da Carbonífera Belluno (2012), nas áreas de extração do mineral, há sempre uma equipe monitorando os efluentes gerados e os recursos hídricos.

As áreas decorrentes de passivos ambientais são recuperadas de acordo com um plano aprovado por órgãos ambientais. Segundo o site da empresa, as ações estão sendo realizadas em seis frentes, sendo elas as seguintes:

a) São Marcos, onde já foram recuperados 21 hectares;

b) Vila Colonial, com área recuperada de 13,6 hectares;

c) Rio Maina, onde os trabalhos ainda não iniciaram, mas serão recuperados 15 hectares;

d) São Roque, onde os trabalhos ainda não iniciaram, mas serão recuperados 31 hectares;

e) A construção da bacia de decantação Rio Fiorita, com obras iniciadas em 2006;

f) Mina Morozini, com 20 hectares de área minerada a céu aberto já recuperado.

$\mathrm{Na}$ área social, a empresa participa de construções importantes para a comunidade em que está inserida. Patrocina times de futebol de campo e de salão amador da cidade, Siderópolis. A associação da Belluno também está aberta para a comunidade, além de ser o local constante das confraternizações entre os colaboradores.

\subsubsection{Carbonífera Criciúma S.A.}

As ações ambientais realizadas pela Carbonífera Criciúma buscam soluções para os impactos gerados no meio ambiente e nas áreas afetadas por sua atividade. Tal desempenho trouxe a empresa à certificação NBR ISO 14001:2004 - Sistemas de Gestão Ambiental. 
No site da Carbonifera Criciúma (2012) consta a implantação de um sistema para tratamento de drenagem ácida de mina, no qual trata $220.000 \mathrm{~m}^{3} / \mathrm{mês}$ de efluentes ácidos.

Além disso, projetos como o financiamento de pesquisa em instituições de ensino e tecnologia como Instituto de Pesquisas Tecnológicas (IPT), Centro de Tecnologia Mineral (CETEM), Universidade Federal de Santa Catarina (UFSC) e Universidade do Extremo Sul de Santa Catarina (UNESC) também são realizados pela carbonífera.

Para a Carbonifera Criciúma S.A., responsabilidade social é sinônimo de bem-estar e diálogo com a sociedade, para se estar em harmonia com o meio em que a organização está inserida. A empresa disponibiliza aos seus colaboradores benefícios, incluindo bolsas de estudo e escolinha de futebol para os filhos.

$\mathrm{Na}$ comunidade em que está instalada, ela incentiva o esporte amador, apoia financeiramente entidades filantrópicas e auxilia na manutenção da escola e da Faculdade Sact.

\subsubsection{Empresas Rio Deserto}

Monitorar as atividades realizadas na extração do carvão, como forma de minimizar o impacto negativo sobre o meio ambiente faz parte das ações das Empresas Rio Deserto (2012), aponta o site. Com esse intuito, programas voltados ao ambiente foram desenvolvidos como, o programa de gerenciamento de resíduos sólidos que propõe a prevenção de impactos ambientais através da reutilização, redução e reciclagem. 0 momento em que se conscientiza os colaboradores sobre a preservação ambiental.

Há, portanto, ações voltadas tanto ao público interno da organização, quanto ao público externo. A Rio Deserto é certificada pela NBR ISO 14001:2004. No site da empresa, no entanto, não consta o total de áreas recuperadas. Como forma de elevar a qualidade de vida da comunidade em que está inserida, as Empresas Rio Deserto desenvolvem e dão apoio a diversas iniciativas.

Entre essas ações, estão as seguintes:

a) distribuição de cestas básicas no bairro Renascer;

b) auxílio na manutenção da escola e Faculdade Satc;

c) projeto Içara Mais Doce, auxiliando e incentivando áreas para a podução de mel;

d) projeto Novo Horizonte, qualificando pessoas para a construção civil;

e) projeto da Estação Biologica Costão da Serra, protegendo e estudando a Mata Atlântica da região, como um laboratório natural; 
f) projeto Felinos do Aguaí, protegendo e conservando os felinos silvestres presente na Serra Geral;

g) projeto Guardiões da Natureza, onde alunos do Bairro da Juventude são capacitados por tecnicos da Rio Deserto para cuidar do meio ambiente e repassar isso aos colegas;

h) projeto Quati, o qual viabiliza o plantio de arvores frutíferas que já não são mais encontradas na região;

i) apoio ao esporte regional;

j) projeto Leite Solidário, onde os colaboradores da empresa doam um litro e leito todo mês, a arrecadação é repassada para entidades e familias carentes;

k) campanha do brinquedo;

I) campanha do agasalho.

\section{METODOLOGIA E AVALIAÇÃO}

No início deste projeto, realizaram-se pesquisas bibliográficas com relação aos conceitos de degradação, sustentabilidade, preservação ambiental. Para tanto, também foram pesquisadas informações por outros meios, a partir de entrevistas com pessoas ligadas ao setor carbonífero.

O survey foi elaborado com base em autores como Hilson (2002) e Lockie (et. al., 2009). Foram aplicados 24 questionários na comunidade do Bairro Ana Maria, em Criciúma. No local, a extração do carvão é feita pelas Empresas Rio Deserto.

\subsection{Análise dos índices obtidos}

Dentre os 24 participantes da pesquisa (parcela da comunidade do Bairro Ana Maria, em Criciúma) moradores da comunidade, dez eram do sexo feminino e 14 eram do sexo masculino. Deles, $46 \%$ afirmam ter uma renda familiar de um a três salários mínimos, outros $42 \%$ alegam ganhar de quatro a sete salários mínimos. Ainda sobre o perfil dos entrevistados, 19 pessoas destacaram residir na comunidade há mais de dez anos.

É importante ressaltar também, que o presidente da associação de moradores do bairro, José Nilton Coradini, deu total apoio à pesquisa. Em entrevista, por ocasião da pesquisa ora exposta, ele destacou que a empresa carbonífera (Rio Deserto, nesse caso) está em constante contato com os moradores. O diálogo é permanente. 
Com relação aos indicadores da realidade socioeconômica da comunidade, foram questionados os participantes da pesquisa sobre a saúde. O bairro possui um posto de saúde, e, de acordo com $75 \%$ dos pesquisados, a indústria carbonífera auxiliou na melhora do serviço da unidade.

Já com relação ao sistema de esgoto, embora o mesmo não apresente mau cheiro ou vazamento, para a maior parte do contingente pesquisado, a situação do sistema continuou igual mesmo com a vinda da mineradora para a comunidade (71\%).

Quando indagados sobre o acesso à água tratada, a comunidade observa que a água é de boa qualidade (79\%), e que não há falta do liquido com freqüência (62\%), e a vinda da carbonífera para o bairro não influenciou na melhora do serviço, como observa $67 \%$.

Com relação há prevenção de incêndios, não há Brigada do Corpo de Bombeiros no bairro, e com relação à melhora ou piora desse serviço com a instalação da mina, os pesquisados se dividem nas opiniões, 38\% apontam que continua igual e $29 \%$ a disseram que melhorou, outros $29 \%$ não responderam a questão.

O policiamento também continuou igual depois do início da extração de carvão na localidade, como indica $52 \%$ dos entrevistados. Um ponto relevante dos dados obtidos é a questão do lazer e recreação. A comunidade aponta (100\%) que esse item melhorou com a instalação das Empresas Rio Deserto.

Embora boa parte da comunidade (67\%) relate que não há locais históricos no bairro, a melhora da paisagem melhorou depois que a empresa mineradora se instalou ali. Outro ponto que também apresentou melhora foi à geração de emprego, $87 \%$ revelaram que o índice aumentou.

A pesquisa também indagou se existe uma comunicação direta e permanente entre a comunidade e a empresa mineradora. Nesse sentido, 91\% dos entrevistados afirmaram que reuniões são feitas com freqüência com a empresa, e com o Ministério Público (61\%).

Desde o inicio da atividade, $50 \%$ dos entrevistados, alegaram que o diálogo melhorou. Cabe salientar que os outros $29 \%$ não responderam a questão.

No survey aplicado à comunidade, foi questionada também a questão ambiental da comunidade. Depois da recuperação da antiga área degradada, 63\% dos pesquisados relataram que a vegetação, as condições dos rios e córregos, a qualidade da água e do ar tiveram melhoras. 50\% afirmaram também que a empresa mineradora procurou melhorar o meio ambiente com a recuperação de áreas degradadas, $29 \%$ não respondeu essa questão.

A forma mais comum de ajudar o meio ambiente foi apontada por $21 \%$ dos entrevistados como apagar as luzes de locais da casa que não estão sendo utilizados.

Outros $17 \%$ apontam a redução do consumo em geral e o reaproveitamento da água, quando possível. Dos $87 \%$ entrevistados avaliaram a recuperação ambiental como muito importante. 
Mesmo com os dados apresentados acima, e com a importância que a comunidade vê no carvão para o desenvolvimento da região (88\%), mais da metade dos entrevistados não conhecem no novo processo de extração do mineral, $41 \%$ apenas afirmaram ter esse conhecimento.

A pesquisa também deixou espaço para que a comunidade pudesse apontar os pontos de conflitos no bairro: $48 \%$ apontaram a falta de infra-estrutura das ruas como sendo o principal problema. E embora o índice de empregos tenha aumentado como já foi citado acima, para $19 \%$ dos moradores, o desemprego também é um gerador de conflito.

\section{CONSIDERAÇÕES FINAIS}

Embora a indústria carbonífera tenha trazido crescimento à região Sul de Santa Catarina, por mais de 30 anos, um rastro de degradação dos recursos naturais também ficou como herança. Em decorrência disso, o carvão passou a ser visto com olhos de desconfiança e negatividade pela população, persistindo, para muitos, uma imagem negativa.

Essa imagem, ainda nos dias atuais, mantém-se em várias instâncias da vida social, tanto a partir da história oral contada pela comunidade regional (sobretudo por aqueles que vivenciaram os períodos de degradação) quanto por meio das mídias.

A falta de apoio e as críticas feitas ao longo do tempo, portanto, exigem, na atualidade, uma intensa e permanente divulgação das ações de recuperação e preservação ambiental hoje promovida pelas carboníferas. Nesse âmbito, a intervenção na recuperação ambiental dos passivos deixados, por meio de Ação Civil Pública movida pelo Ministério Público, impulsionou o setor a repensar suas ações no que tange aos cuidados com o meio ambiente em que estão inseridas e ao diálogo constante com as comunidades mineradas, consequentemente.

Diante dos indicadores de percepção comunitária pesquisada e dos índices obtidos durante a pesquisa, é notório que as empresas mineradoras estão realizando ações com vistas a cumprir a determinação da Justiça, mas acima de tudo com objetivo de melhorar a convivência com as comunidades.

O apoio da população, aliás, é fator essencial para o fortalecimento das empresas do setor e o estreitamento da relação com a comunidade, em primeira instância, e com a sociedade em geral. Para tanto, a criação de canais de comunicação eficazes e permanentes, o que se pôde como na comunidade pesquisada (Bairro Ana Maria), tem sido, pelo visto, uma preocupação da empresa que recupera as áreas degradadas na referida localidade.

Ao perceber a visão que a comunidade evidenciou ao se referir à empresa mineradora, Rio Deserto, foi possível verificar que há uma preocupação, por parte da organização, em atender 
ao anseio da comunidade, sobretudo no que tange ao destino das áreas recuperadas, o que era um dos objetivos traçados no planejamento deste trabalho. Hoje em dia, a comunidade desfruta de um campo para prática desportiva, o qual funciona em áreas recuperadas pela empresa. Tal expectativa tem sido atendida pela empresa mineradora, justamente por esta manter com a comunidade do Bairro Ana Maria uma comunicação contínua e, pelo que foi visto nas respostas dos moradores pesquisados, eficaz.

Atualmente, pelo que se pôde perceber por meio da aplicação do survey, o setor carbonífero tem procurado fazer da população como uma aliada, a partir de um diálogo permanente. No caso ora estudado, percebeu-se que a finalidade da empresa, ao promover essas ações, é estreitar laços de confiança, tanto para contribuir na melhoria da qualidade de vida da comunidade, quanto para melhorar o relacionamento (e a imagem do setor) junto à sociedade.

\title{
DIALOGUE BETWEEN THE COMMUNITY AND COAL INDUSTRIES: COMMUNITY PERCEPTION RESEARCH BASED ON SOCIAL AND ENVIRONMENTAL INDICATORS
}

\begin{abstract}
This article aims at analyzing the communication between the community and the coal industry in the southern region of Santa Catarina, considering, as a parallel topic, the destiny of areas subject to environmental damage. The object of the analysis is the quantitative evaluation of a community in which an organization, operating in the coal mining sector, recovered areas previously degraded. To understand the context of the research, a brief history of coal mining will be considered, as well as a description of the activities of some mining companies in the area of Criciúma.
\end{abstract}

Keywords: Mining. Community. Environmental responsibility. 


\section{REFERÊNCIAS}

ASSOCIAÇÃO BRASILEIRA DO CARVÃO MINERAL. História do carvão no Brasil. Criciúma, 2012. Disponível em: <http://www.carvaomineral.com.br>. Acesso em: 19 set. 2012.

BELOLLI, Mário et. al.. História do Carvão de Santa Catarina. Criciúma: Imprensa Oficial do Estado de Santa Catarina, 2002.

BRASIL. Decreto no 97.632, de 10 de abril de 1989. Dispõe sobre a regulamentação do Artigo $2^{\circ}$, inciso VIII, da Lei $n^{\circ} 6.938$, de 31 de agosto de 1981 , e dá outras providências. DOU, 1989. Disponível em: <http://www.planalto.gov.br/ccivil_03/decreto/1980-1989/ D97632.htm>. Acesso em: 19 set. 2012.

CARBONÍFERA BELLUNO. 2012. Disponível em: <http://www.cbelluno.com.br>. Acesso em: 20 set. 2012.

CARBONIFERA CRICIÚMA. 2012. Disponível em: <http://www.carboniferacriciuma.com. br/site>. Acesso em: 19 set. 2012.

DIAS, Reinaldo. Gestão ambiental: responsabilidade social e sustentabilidade. São Paulo: Atlas, 2009.

EMPRESAS RIO DESERTO. 2012. Disponível em: <http://www.riodeserto.com.br>. Acesso em: 24 set. 2012.

HILSON, G. An overview of land use conflicts in mining communities. Land Use Policy, vol. 19, pp. 65-73, 2002.

LOCKIE, S. et. al..Coal mining and the resource community cycle: a longitudinal assessment of the social impacts of the Coppabella coal mine. Environmental Impact Assessment Review, vol. 29, pp.330-339, 2009.

PAREJO, Luiz Carlos. A fonte energética mais utilizada depois do petróleo. Disponível em: <http://educacao.uol.com.br/geografia/ult1694u298.jhtm>. Acesso em: 26 de Jan. de 2011.

SCLIAR, Cláudio. Mineração e Geodiversidade do planeta Terra: mineração nos Planos Curriculares Nacionais do Ensino Fundamental e Médio. Ed. Signus, São Paulo, 2009. 


\section{SOBRE AS AUTORAS}
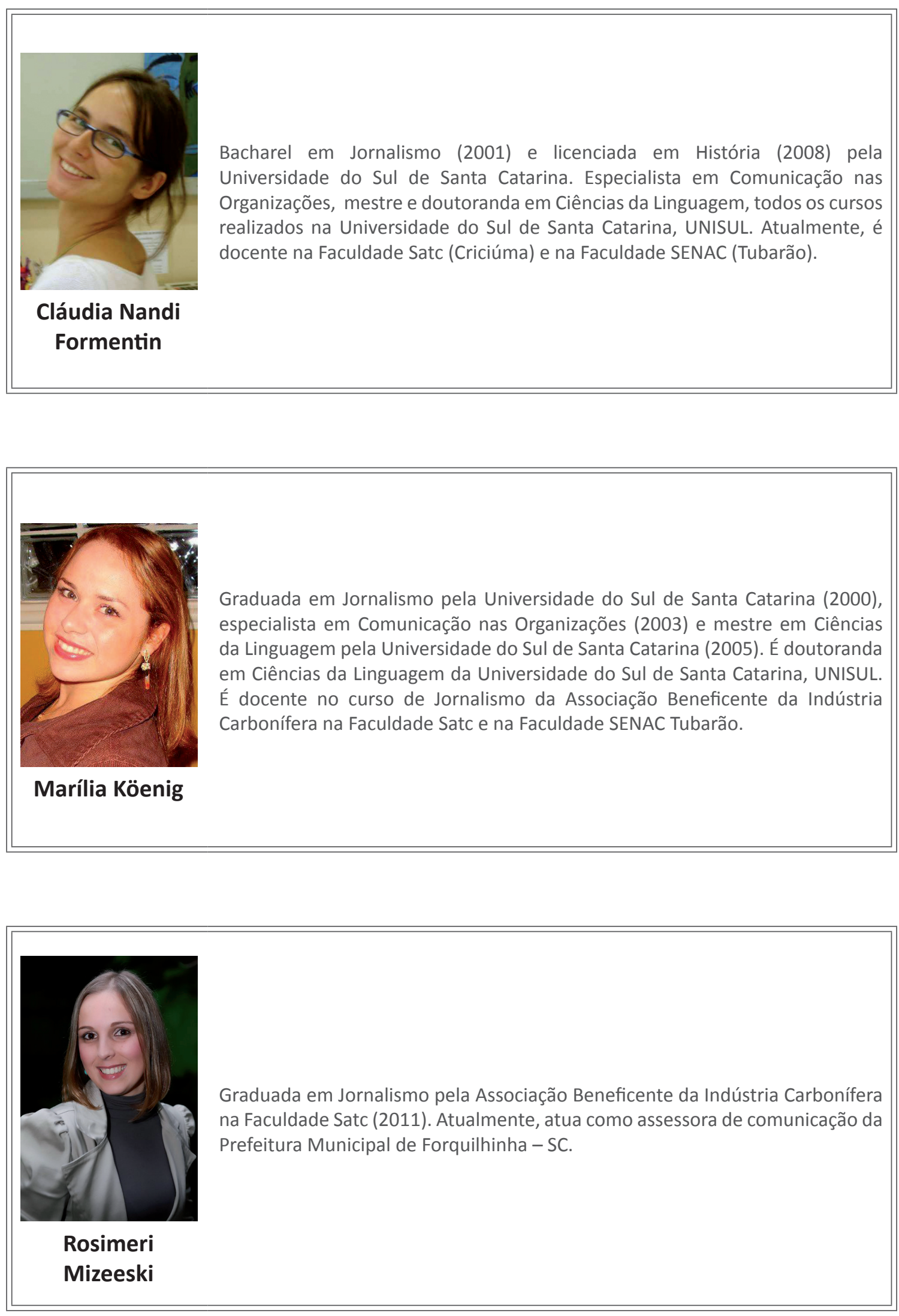